\title{
THE ANALYSIS OF THE NEAR-SURFAGE ENERGY TRANSFER ENVIRONMENT FROM THERMAL INFRARED IMAGERY
}

\author{
By Sam I. Outcalt
}

(Department of Geography, University of Michigan, Ann Arbor, Michigan 48ro4, U.S.A.)

\begin{abstract}
The radiant surface temperature imaged by thermal infrared line-scanning equipment is a product of both surface temperature and emissivity. In detail it is the integrated product of the evolutionary development of the near-surface energy transfer regime. The variation of surface radiant temperature spatially and temporally contains information about the structure, composition, and thermal state of near surface materials. It is suggested that the study of ground ice, sea/lake ice, and the thermal regimes of mountain snow and ice bodies, are reasonable targets for the quantitative application of thermal mapping technology, and that considerable technical development effort be expended on spectral, spatial, and temporal operators for use in computer processing of pictures for glaciological data.

RÉsumÉ. L'analyse du milieu d'échange d'energie proche de la surface à partir d'une image aux rayons infrarouges calorifiques. L'image de la température superficielle de rayonnement transmise par un équipement de balayage à rayons infrarouge calorifique, est le résultat conjugué de la température de surface et de l'émissivité. En détail, c'est le résultat de l'intégration du développement fluctuant du régime de transferts énergétiques près de la surface. La variation de la température superficielle de rayonnement dans l'espace et dans le temps contient des informations sur la structure, la composition et l'état thermique des matériaux proches de la surface. On pense que les études de la glace de terre, de la glace de lac ou de mer, des régimes thermiques de la neige des montagnes et des glaciers, sont des objectifs raisonnables pour une application quantitative de la technique de cartographie thermique, et qu'il faut faire un effort technique considérable sur les paramètres de temps, d'espace et de longueur d'onde pour utiliser sur ordinateur les images obtenues à des fins glaciologiques.

Zusammenfassung. Die Analyse der Energieübertragung in der Umgebung einer Oberfläche aus Abbildungen mit thermischem Infrarot. Die Strahlungstemperatur einer Oberfläche, die mit Geräten zur linienweisen Abtastung im thermischen Infrarot ermittelt wird, ist sowohl von der Temperatur wie von der Strahlungskraft der Oberfläche abhängig. Genau genommen ist sie das Gesamtergebnis der Entwicklung des Energieübertragungssystems in der Nähe der Oberfläche. Die Veränderung der Strahlungstemperatur der Oberfläche enthält räumlich und zeitlich Informationen über die Struktur, die Zusammensetzung und den thermischen Zustand der oberflächennahen Materialien. Die Untersuchung von Bodeneis, Meer- und Seeeis sowie der thermischen Verhältnisse der Schnee- und Eiskörper im Gebirge erscheint daher als lohnendes Ziel für die quantitative Anwendung der Verfahren zur thermischen Abbildung. Für die technische Entwicklung spektraler, räumlicher und zeitlicher Sensoren deren Daten zur digitalen Bildverarbeitung in der Glaziologie verwendet werden können, sollten beträchtliche Anstrengungen unternommen werden.
\end{abstract}

\section{INTRODUGTION}

This paper covers the intersection of several topics in which the research and development technology is both rapidly expanding and complex. It is therefore necessary at the outset to establish certain bounds for the discussion which will follow. First, glaciology is here considered in its broadest context including the study of sea ice, massive ground-ice bodies, and snow hydrology. It is within these areas that the technology described in this paper is now being applied and evaluated. Secondly, special emphasis will be given to the explicit deterministic analysis of thermal contrast as it evolves as the natural product of the evolution of the nearsurface energy-transfer regime. Thirdly, the sensor will be assumed to be a scanning radiation thermometer located at an unspecified elevation above the surface. It is further assumed that sensor information will be collected in such a manner that thermal images can be manufactured. Lastly, no effort will be made to treat the problems of scan geometry or atmospheric attenuation as these topics are already covered in the literature. Excellent short articles on these and other hardware-related problems are available (e.g. McLerran, i968; Lorenz. I973; Pease, I971).

In short, this presentation will be focused on the evaluation of the surface thermal regime in cold regions. Near-surface material variations produce some spatial and temporal thermal contrast (the signal) which is often masked by topographic and other effects (noise). The 
problem will be considered as one in exploration geophysics. A deterministic framework will be employed rather than image interpretation following the empirical qualitative methods of more traditional remote-sensing and photo-interpretative analysis. Within this context modeling and observation are interwoven.

\section{The information content of thermal imagery}

The radiative flux density $Q$ emitted from a point at the Earth's surface is controlled by the absolute temperature $T$ and the thermal emissivity $E$ of the emitting surface as

$$
Q=E \sigma T^{4}
$$

where $\sigma$ is the Stefan-Boltzmann constant.

LeSchack and others (1973) have indicated that the ratio of the responses of sensors at different wavelengths in the relatively attenuation-free regions of the infrared $(4-5$ and 8-12 $\mu \mathrm{m}$ ) indicate surface emissivity variation, as the surface temperature is independent of wavelength. Techniques for two-channel mixing by algebraic operators may eventually reduce some of the uncertainty introduced by emissivity variation.

Beyond these considerations it should be recognized that the surface thermal response is not independent of the thermal history of the near-surface zone but is conditioned by that history of diurnal evolution nested within annual evolution. The mechanics of this process can be understood in an abstract manner by examining the conceptual structure of a simple surface climate simulator (Outcalt, I972[a]).

The surface temperature in a small area is influenced by three sets of variables which are astronomical, meteorological and geographical. These are outlined in Table I.

TABle I. Surface temperature influence SETS

Sets

Astronomical $(A)$

Meteorological $(M)$

Geographical $(G)$

\section{Variables}

Solar elevation (time of day, year).

Cloud cover, atmospheric transparency, air temperature and humidity, wind velocity and pressure.

Radiative properties of surface (albedo, emissivity), substrate thermal properties, substrate temperature, aerodynamic roughness of surface, wetness of surface, slope and exposure, horizon geometry.

When viewed in this manner the familiar energy balance or conservation rule becomes a powerful analytical vehicle (Myrup, I969; Outcalt, I972[a]). The four components of the surface energy-transfer regime can now be considered as complex functions of these three variable sets and the surface temperature $\mathcal{T}$. Thus, the relationship between the net radiation $R$, soil $S$, and sensible $H$, and latent $L$ heat fluxes can be expressed as a variation of the energy balance equation

$$
R(A, M, G, T)+S(G, T)+H(M, G, T)+L(M, G, T)=0 .
$$

The specific variables used in the computation of each component are discussed in detail by Outcalt (1972[a]). If all the variables sets are specified, the equation becomes a transcendental function of surface temperature alone. That surface temperature which will balance the heat flow across a surface is calculated by the sequential substitution of estimates into a suitable numerical algorithm which drives the conservation equation toward zero. When that condition is approached under conditions of correct variable set specification within a wellconditioned model structure, the model surface temperature, the substrate temperatures, and the components of surface energy transfer, match reality. In nature the soil thermal regime evolves through time $t$ as a function of the second derivative of temperature $T$ in a 
complex environment where substrate thermal diffusivity $\alpha$ is a function of both depth and temperature (due to freeze-thaw, etc.). This non-linear (parabolic) partial differential equation is

$$
\partial T / \partial t=\alpha(Z, T) \partial^{2} T / \partial Z^{2} .
$$

Thus the observed surface thermal response is conditioned by the near-surface thermal profile which evolved during a previous history of interaction between the variables listed in Table I. In an iterative, finite-difference model this feedback effect is simulated by nesting the substrate thermal diffusion loop (Equation (3)) within the equilibrium temperature solutionsearch loop (Equation (2)). This model structure has successfully reproduced the thermal and evaporation contrast as measured on the ground in the extremely complex topographic environment of an Alaskan alpine pass at five field micrometeorological sites with differing slope, exposure, horizon geometry and stratigraphy (Brazel and Outcalt, I973[a], [b]), (see Figs $\mathrm{I}$ and 2). It has also been used to predict the observed thermal image contrast produced by thaw lakes beneath snow cover, sea-ice thickness (age), and thermal plumes resulting from human construction activity on the smooth snow-covered surface of the Arctic coastal plain (Outcalt, I972[b], 1973), (see Figs 3 and 4). These contrasts resulting from differences in the radiative, thermal, and aerodynamic properties are best documented by imagery acquired along fixed flight lines at several times during the diurnal cycle. The phase and amplitude response of the observed thermal regime can then be compared to model response (see Fig. 5). The influence of the heat of fusion, which decreases the thermal diffusivity in ice-rich soils, has been documented and discussed in some detail by Nakano and Brown (1971), and Outcalt ( $1972[\mathrm{c}])$.

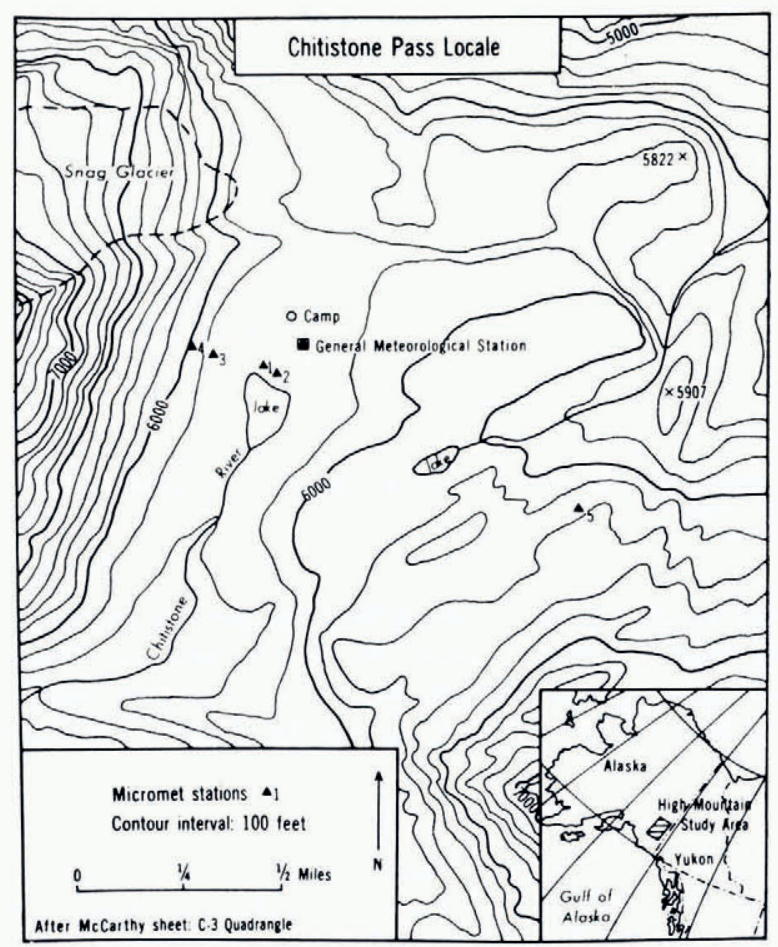

Fig. 1. The positions of the micrometeorological stations at Chitistone Pass, Alaska. $\frac{1}{2}$ mile $=304 \mathrm{~m}, 100$ feet $=30.5 \mathrm{~m}$. 

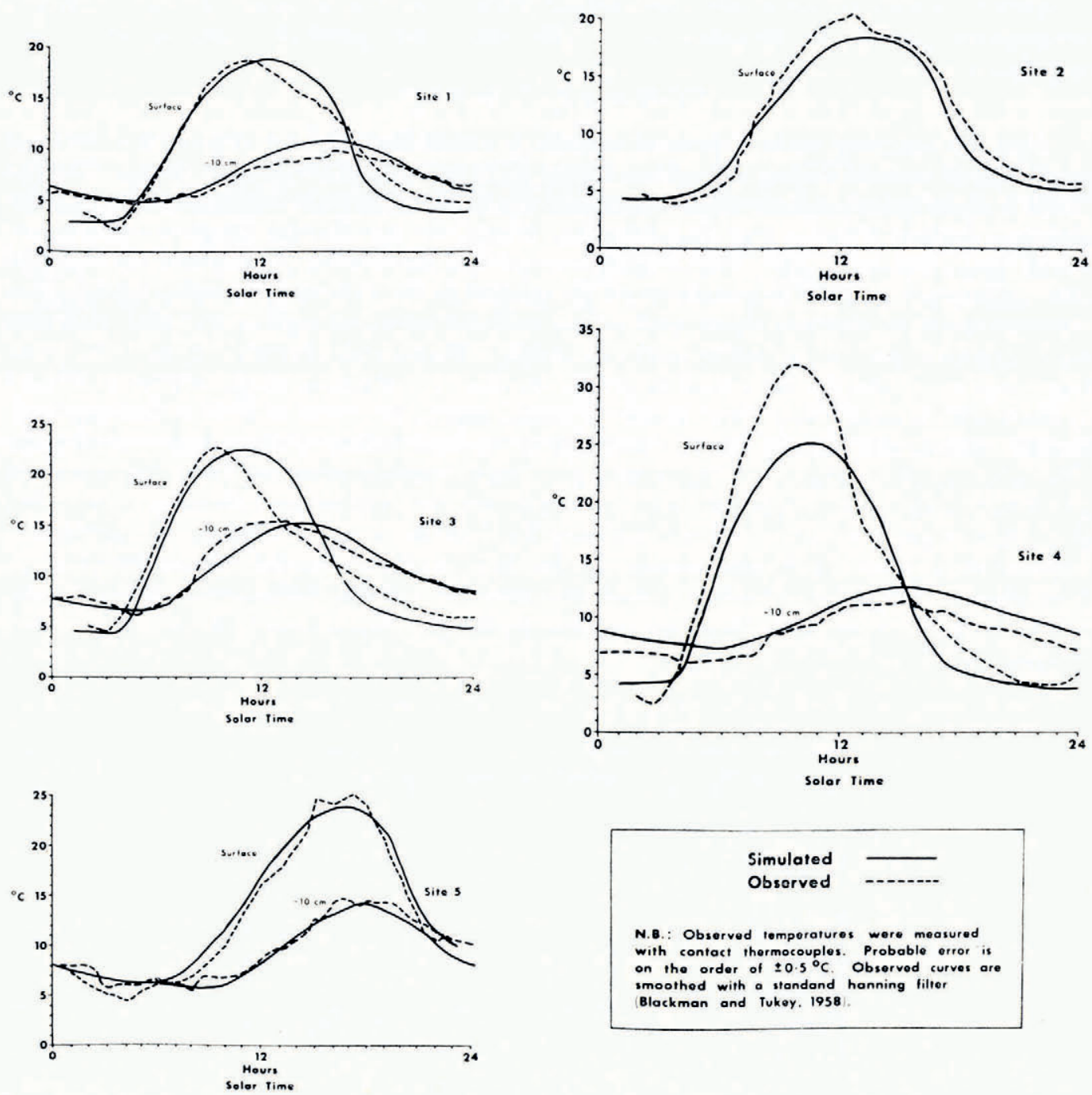

Fig. 2. The simulated and observed thermal regimes at the Chitistone Pass micrometeorological stations. Clear weather midsummer observations were simulated.

At present, thermal modeling can be employed for the deterministic analysis of contrast in thermal infrared line-scan imagery. Target contrast is maximum under conditions of clear sky and low wind, and pre-flight modeling can be employed to select that portion of the diurnal cycle when contrast between target and background is optimum.

\section{Some Previous APPLiCATIONS IN GLACIOLOGY}

In the past, thermal imagery has been analyzed largely in an empirical manner to detect crevasses and study the structure of sea ice (e.g. Poulin and Harwood, r966; McLerran, I964[a], [b]). Horvath and Brown ( I97 I) carried out a detailed analysis of sea ice and snowcovered tundra terrain near Barrow, Alaska utilizing numerous wavelength regions to estimate 


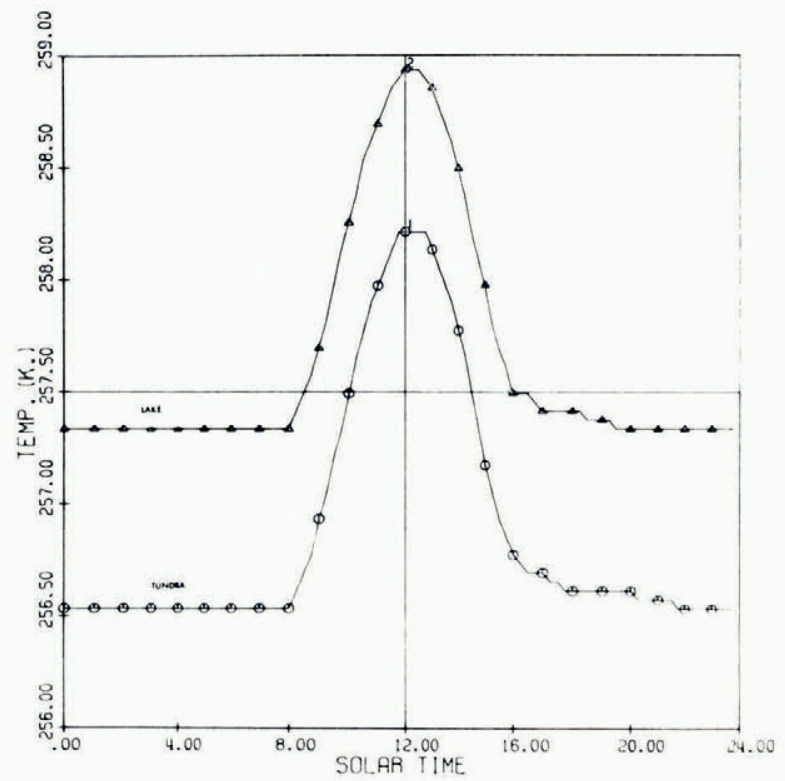

Fig. 3. The simulated surface contrast of the snow-covered tundra and thaw lakes shown in Figure 4.

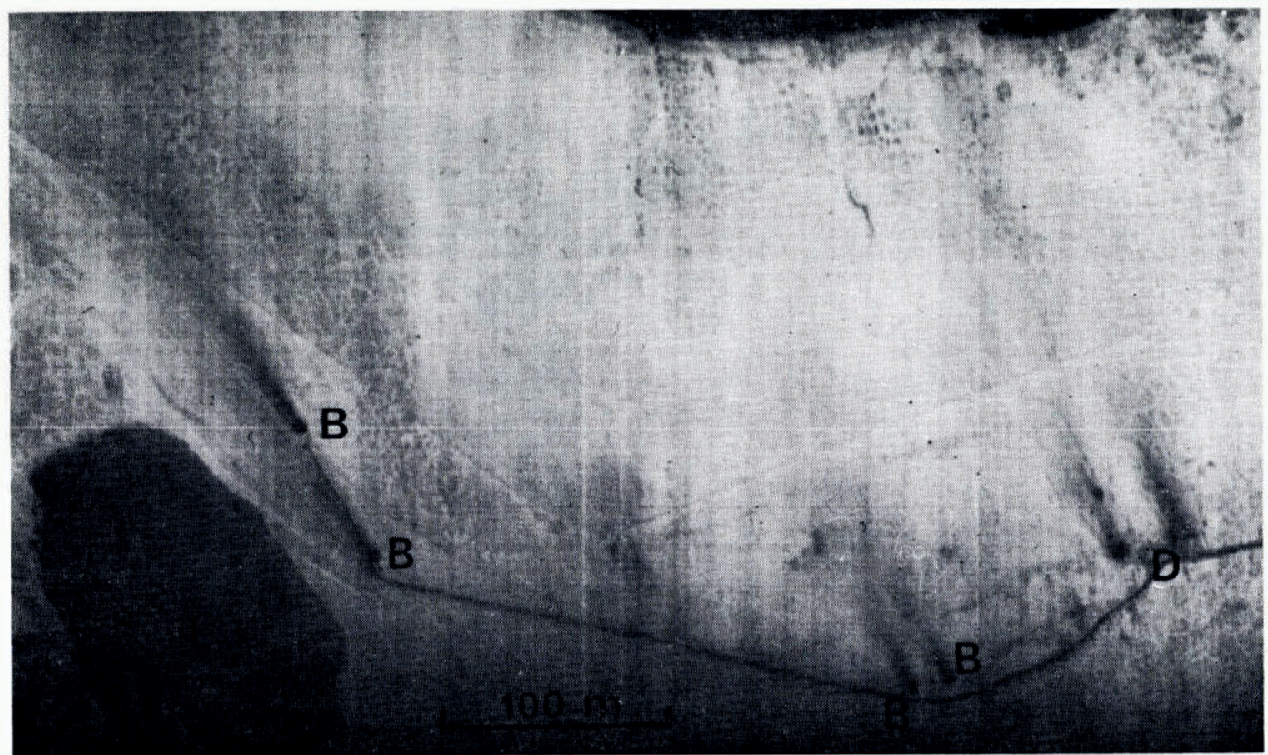

Fig. 4. Thermal imagery acquired south of the NARL site, Barrow, Alaska, I7.I5 A.S.T., II October I967. Dark (hot), light (cold). Note the warm plumes extending to the lee of the drum dumps $(D)$ and unheated buildings $(B)$, along the service road which is relatively warm compared to the snow-covered tundra surface. Snow-covered frozen lakes $(L)$ and lowcenter polygons also appear to be relatively warm. Imagery courtesy of Environmental Institute of Michigan (formerly Willow Run Laboratories). 
instantaneous net radiation values for specific target areas. Multispectral hardware and data reduction technology is advanced to a stage where it may soon be possible to produce computer maps of net radiation directly from data tapes containing multi-spectral information (Malila and Wagner, r972).
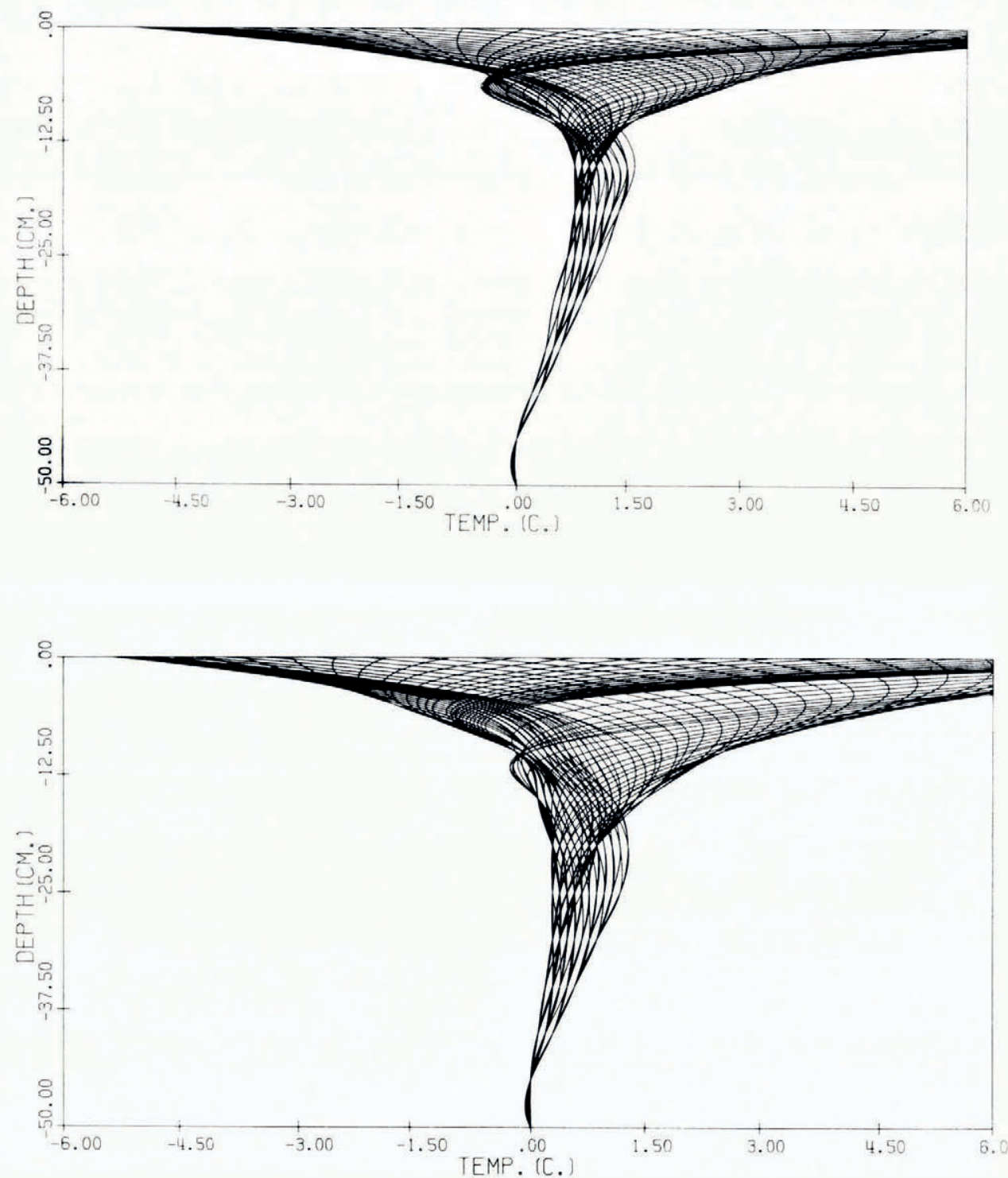

Fig. 5. The solution of Equation (3) within the simulation of the effects of removing a $15 \mathrm{~cm}$ organic layer, exposing mineral soil, from the tundra at Barrow, Alaska. A late August, clear, calm environment was simulated. One thermal profile was generated each ${ }_{15} \mathrm{~min}$ during the diurnal cycle. The upper set of curves assume the organic layer to be present; the lower ones correspond to no organic layer. Note the effect of freeze-thaw retarding the evolution of the substrate thermal structure, as shown by the clustering of lines just below the freezing point in the upper levels, and the increased amplitude of the disturbance after the removal of the low-diffusivity, overlaying, organic material. 


\section{Potential applications in Glaciology}

The technology of thermal mapping has now evolved to the stage where it is a routine matter to process calibrated imagery into computer-compatible, digital form on magnetic tape. There is no justification within this hardware environment for using only the qualitative photo-interpretation mode of image analysis. Within glaciology, there are at least three areas where experiments in thermal mapping and modeling should yield valuable results:

\section{(I) Sea and lake ice thickness forecasting}

Simulation experiments, verified with off-shore imagery acquired near Barrow, Alaska, in October 1967 , indicated that the surface thermal contrast in sea ice ranging in age from "polar floe" to "seasonal" could be successfully modeled. This analysis demonstrated that ice thickness (age) was positively correlated with solar albedo and negatively correlated with surface temperature (Horvath and Brown, I97I). The thickness of sea ice in the imagery varied from $\mathrm{I} 5$ to $210 \mathrm{~cm}$ and was assumed to be overlain by ${ }_{1} 5 \mathrm{~cm}$ of packed snow in the simulation (Outcalt, 1973).

The movement of men and material onto ice cover which is at least partially seasonal is becoming more common in the high latitudes each winter season. Some effort should be expended on the prosecution of an integrated modeling and field-measurement experiment under conditions in which solar radiation is insignificant and thaw zones are present in the ice cover. Attention should also be paid to the effects of variable depth and structure of the snow cover (Poulin, I975). The goal of this venture should be the designing and testing of a "conservative ice-thickness model" which would permit underestimation of thickness but exclude the possibility of overestimation.

\section{(2) Snow hydrology}

Melting snow cover shows no thermal contrast due to local relief or material effects (e.g. wind-packed, fresh snow). Thus, thermal imagery may provide the ideal geophysical tool for monitoring the seasonal ripening of snow in mountain regions (personal communication in 1973 from A. D. C. Terroux). Simple imagery systems could be initially employed on scheduled commercial and military aircraft, limiting data acquisition to clear weather.

\section{(3) Man-induced thermal modification}

When man builds structures at high latitudes, the aerodynamic and radiative properties of the surface are frequently altered, and the thermal properties of the surface changed due to disturbances of the local hydrologic network and installation of construction materials. The "thermal plumes" down-wind from man-made structures discussed earlier provide a vivid example. Thermal imagery is an excellent device for documenting the changes in the surface thermal regime produced by "high-latitude urbanization". This type of documentation is the first step in attenuating undesirable side effects of construction. The urban heat-island effect is of more than academic interest in the circumpolar world where large structures are frequently built on ice-rich soils, and the existence of a heat-island effect can lead to structural failure and/or increased maintenance costs.

\section{SOME PRIORITIES FOR FUTURE RESEARGH}

As the thermal-response data are often collected on magnetic tape, there is a great potential for channel-mixing algebraic operations and spatial filtering of raw data. Maps of diurnal thermal range (e.g. produced by subtraction of values on a pre-dawn map from those on a noon map) would contain patterns related to material properties, etc. Unfortunately these 
time-dependent operators require a sophisticated registration technology to remove scanner distortion and effects due to flight-path variation. To the author's knowledge no geographic registration system suitable for aircraft data is operational! Picture processing technology could be applied to raw images or processed images to smooth information (to reveal underlying low-frequency patterns), outline areas of sharp gradient changes (two-dimensional second-derivative filter) and remove high-frequency noise. This technology has been developed to an extremely high degree (Rosenfield, r969; Tobler, r966). Spatial smoothing operators are particularly necessary to remove the effects of slope and exposure in micro-relief, which will produce high-frequency thermal contrast at low sun angles during the Arctic summer. In short, three classes of algebraic operators are suggested. These may be applied in an almost infinite sequence and are described in Table II.

Table II. Examples of temporal, spatial, AND SPEctral operators

$\begin{array}{lll}\text { Temporal operators: } & T_{\mathrm{s}} \text { subtract values on map at time I from those on map at time } 2 \\ & T_{\mathrm{r}} \text { ratio of values on map at time I to those on map at time } 2 \\ \text { Spatial operators: } & S_{\mathrm{m}} \text { smoothing (preserve low frequencies) } \\ & S_{\mathrm{d}} \text { second-derivative filter (enhance gradient areas of steep } \\ \text { Spectral operators: } & C_{\mathrm{s}} \text { subtract signals from two different spectral regions } \\ & C_{\mathrm{r}} \text { ratio signals from two different spectral regions }\end{array}$

Thus the sequence to prepare a smoothed map of emissivity variation would be $\left(C_{\mathrm{r}} * S_{\mathrm{m}}\right)$. The operation of preparing a thermal range map initially smoothed thrice and then highlighted to display areas with rapid gradient change would be $\left(T_{\mathrm{s}} * S_{\mathrm{m}} * S_{\mathrm{m}} * S_{\mathrm{m}} * S_{\mathrm{d}}\right)$. The possibilities are nearly limitless.

In short, effort should be applied first to the problem of registration technology and secondly to the design of temporal, spatial, and spectral operators which can be applied directly to tapes of raw data and used in the computer to generate graphic output.

\section{Conclusion}

Thermal imagery and contrast analysis cannot be separated from the evolutionary energytransfer environment of which it is an integrated expression. The recognition of the interrelationship between geographic material variations and their expression through the evolution of the surface thermal regime is the key to utilizing the information content of imagery. In a parallel vein the potential power of modeling and data manipulation analysis is enhanced by the reduction of the effective thermal diffusivity during freeze-thaw. The potential of the existing technology can be realized by (I) the development of systems for operational data reduction utilizing temporal, spatial and spectral operators, (2) field experiments combining modeling, aerial data acquisition, and ground measurements, to establish the limits of recognition systems.

\section{Acknowledgements}

The imagery at Barrow, Alaska, was acquired during a joint research project of Willow Run Laboratories (now Environmental Research Institute of Michigan) and Arctic Institute of North America sponsored under contract by the Office of Naval Research (ONR-426). The Chitistone Pass micrometeorological data were gathered as part of the Arctic Institute of North America-High Mountain Environment Project funded by the U.S. Army Research Office, Durham, North Carolina. 


\section{REFERENCES}

Blackman, R. B., and Tukey, J. W. 1958. The measurement of power spectra. New York, Dover Publications, Inc. Brazel, A., and Outcalt, S. 1973[a]. The observation and simulation of diurnal surface evaporation contrast in an Alaskan alpine pass. Fournal of Applied Meteorology, Vol. 12, No. 7, p. 1 134-43.

Brazel, A., and Outcalt, S. 1973[b]. The observation and simulation of diurnal surface thermal contrast in an Alaskan alpine pass. Archiv für Meteorologie, Geophysik und Bioklimatologie, Ser. B, Vol. 21, Nos. 2-3, p. $157-74$.

Horvath, R., and Brown, W. L. 1971. Multispectral radiative characteristics of Arctic sea ice and tundra. Ann Arbor, Infrared and Optics Laboratory, Willow Run Laboratories, University of Michigan. (Final Report ONR-426.)

LeSchack, L. A., and others. 1973. Potential use of airborne dual-channel infrared scanning to detect massive ice in permafrost, [by] L. A. LeSchack, F. H. Morse, W. R. Brimley, Jr., N. G. Ryan and R. B. Ryan. Permafrost. Second International Conference, 13-28 July 1973, Yakutsk, U.S.S.R. North American contribution. ... Washington, D.C., National Academy of Sciences, p. 542-49.

Lorenz, D. 1973. Problems of airborne infrared scanning in meteorology. Archiv für Meteorologie, Geophysik und Bioklimatologie, Ser. B, Vol. 2 I, Nos. 2-3, p. 125-46.

Malila, W. A., and Wagner, T. W. 1972. Multispectral remote sensing of elements of water and radiation balance. Proceedings of the eighth International Symposium on Remote Sensing of Environment . . 1972. . . Ann Arbor, Willow Run Laboratories, Institute of Science and Technology, University of Michigan, p. $639^{-63}$.

McLerran, J. H. 1964[a]. Airborne crevasse detection. Proceedings of the third Symposium on Remote Sensing of Environment ... 1964. .... Ann Arbor, Willow Run Laboratories, Institute of Science and Technology, University of Michigan, p. 801-02.

McLerran, J. H. $1964[\mathrm{~b}]$. Infrared sea ice reconnaissance. Proceedings of the third Symposium on Remote Sensing of Environment ... 1964. ... Ann Arbor, Willow Run Laboratories, Institute of Science and Technology, University of Michigan, p. 789-99.

McLerran, J. H. 1968. Infrared sensing of soils and rock. Material Research and Standards, Vol. 8, No. 2, p. I 7-2 1.

Myrup, L. 1969. A numerical model of the urban heat island. Fournal of Applied Meteorology, Vol. 8, No. 6, p. $908-18$.

Nakano, Y., and Brown, J. I97 I. Effect of a freezing zone of finite width on the thermal regime of soils. Water Resources Research, Vol. 7, No. 5, p. 1226-33.

Outcalt, S. 1972[a]. The development and application of a simple digital surface climate simulator. Fournal of Applied Meteorology, Vol. i I, No. 4, p. 629-36.

Outcalt, S. $1972[\mathrm{~b}]$. The simulation and implications of thermal plumes produced by Arctic construction in smooth terrain. Archiv für Meteorologie, Geophysik und Bioklimatologie, Ser. B, Vol. 20, Nos. 3-4, p. 26 I-67.

Outcalt, S. $1972[\mathrm{c}]$. The simulation of subsurface effects on the diurnal surface thermal regime in cold regions. Arctic, Vol. 25, No. 4, p. 306-o8.

Outcalt, S. 1973. The simulation of dirunal surface thermal contrast in sea ice and tundra terrain. Archiv für Meteorologie, Geophysik und Bioklimatologie, Ser. B, Vol. 21, Nos. 2-3, p. 147-56.

Pease, R. W. I971. Mapping terrestrial radiation emission with a scanning radiometer. Proceedings of the seventh International Symposium on Remote Sensing of Environment ... I971. . . Ann Arbor, Willow Run Laboratories, Institute of Science and Technology, University of Michigan, Vol. I, p. 50I-10.

Poulin, A. O. 1975. Significance of surface temperature in the thermal infrared sensing of sea and lake ice. Fournal of Glaciology, Vol. i 5 , No. 73, p. 277-83.

Poulin, A. O., and Harwood, T. A. 1966. Infrared imagery in the Arctic under daylight conditions. Proceedings of the fourth Symposium on Remote Sensing of Environment ... 1966. . . Ann Arbor, Willow Run Laboratories, Institute of Science and Technology, University of Michigan, p. 23I-41.

Rosenfield, A. 1969. Picture processing by computer. New York, Academic Press.

Tobler, W. R. 1966. Numerical map generalization and notes on the analysis of geographic distribution. Ann Arbor, Dept. of Geography, University of Michigan. (Discussion Paper, Michigan Inter-University Community of Mathematical Geographers, 8.)

\section{DISCUSSION}

W. F. WEEKS: I certainly agree with your comment that it is extremely difficult to utilize infrared imagery to calculate the thickness of either sea or lake ice independent of ground truth, regardless of how well the imagery is calibrated. However if you have ground truth, and by that I mean the direct measurement of ice thickness, you can usually use this plus the infrared imagery to give reasonable ice thickness estimates in the "near" vicinity of the groundtruth site. The reason for this is that, in general, all ice of the same thickness (which presumably formed at the same time) will be covered by the same thickness of snow and therefore will have the same surface temperature.

Outcalt : I might also mention that in some sense it may be good to have a "blurry" measurement since the simulation technique has to be performed over some areal average. 
M. DE Quervain: What was the snow depth and the local air temperature for the photograph showing the thermal plumes?

S. I. Outcalt: Snow depth was $\approx 20 \mathrm{~cm}$ and the local air temperature about $5^{\circ} \mathrm{C}$.

M. E. R. WALFORD: These thermal plumes are interesting. Have you ever observed cold plumes? Also, plumes may presumably occur over a wide range of scales of size, and thus determine surface temperatures. Can you comment on this?

Outcalt: Our studies show that roughness changes certainly do cause major changes in surface temperatures. This effect is especially pronounced in cities. Another good example is the snow fence constructed at Barrow: it changes the temperature regime markedly. 